\title{
Assessment of Nutritional Status and Associated Factors among Prisoners Living with HIV/AIDS in Kality Prison, Addis Ababa, Ethiopia
}

\author{
Tsebaot Kassa, Atsede Alle and Mehret Tesfu*
}

College of Medicine and Health Sciences, Debre Markos University, Debre Markos, Ethiopia

\begin{abstract}
Introduction: In the case Human Immune Deficiency virus/Acquired Immune Deficiency Syndrome (HIVIAIDS), prison conditions not only contribute to the risk of transmission, it also hastens the progression of HIV and deterioration in the health of prisoners living with HIVIAIDS. Prisons typically comprise marginalized sections of society and at high nutritional risk due to lack of diet diversity, as these prisoners depend on few kinds of food for a long time and in a situation, adequacy of nutritional requirement is a great issue of concern.
\end{abstract}

Objective: To assess nutritional status and associated factors among prisoners living with HIVIAIDS in Kality prison, Addis Ababa, Ethiopia, 2016

Method: Institution based cross sectional study design was conducted among randomly selected 412 prisoners on pre Anti-Retroviral Therapy and Anti-Retroviral Therapy in Kality prison, Addis Ababa, Ethiopia from February to March, 2016. The data entered to Epi-info version 7.0 and export to Statistical Package for Social Science version 20.0 for further analysis. Descriptive statistics, binary and multivariable logistic regression analysis were employed to identify nutritional status and associated factors that affect nutritional status of prisoners living with HIVIAIDS

Results: The overall magnitude of malnutrition was found to be $43 \%$ among prisoners living with HIVIAIDS. Female respondents were $92 \%$ times less likely to develop malnutrition than male respondents (AOR $0.08[95 \% \mathrm{Cl}$ $0.02,0.42$ ) and those who were in the age range of $\geq 50$ were eight times more likely to be malnourished with (AOR $8.68[95 \% \mathrm{Cl} 1.59,47.28])$ than other age groups.

Conclusion: The prevalence of underweight was very high among prisoners living with HIVIAIDS in this area.

Recommendation: The prison administrative body should give emphasis on increasing diversified food and Proper nutritional assessment should be the vital part of HIV care management by health workers.

Keywords: Prisoners; HIV/AIDS; Nutritional status

Abbreviations: AA: Addis Ababa; AIDS: Acquired Immune Deficiency Syndrome; ART: Anti-Retroviral Therapy; BMI: Body Mass Index; CD4: Cluster of Differentiation 4; ETB: Ethiopian Birr; FAO: Food and Agriculture Organization; HAART: Highly Active Anti Retro Viral Therapy; HIV: Human Immune Deficiency Virus; MSF: Medicines sans Frontiers; MSM: Men who have Sex with Men; OI: Opportunistic Infections; PLWHIV/AIDS: People living With HIV/ AIDS; RUTF: Ready to Use Therapeutic Food; SPSS: Statistical Package for Social Science; TB: Tuberculosis; USA: United States of America; WHO: World Health Organization

\section{Introduction}

Prison is an institution that holds people who have been sentenced to a period of imprisonment by the courts for offences against the law. On the other hand, a prisoner also known as inmate or detainee, is a person who is deprived of liberty against his or her will and have no control over their environment as a result of their incarceration [1]. Since prisoners are not free living people, they usually depend on prison diet and have no control over the quality and quantity of meals consumed [2].

Since the first reports of HIV/AIDS in prisons published more than 25 years ago, the prison health issue has been the most highly researched worldwide. Studies on prison populations in most countries have consistently reported rates of HIV infection in prisons exceeded than the general population. Most time, access to health care in prison settings is limited and not equivalent to the services that are available in the wider community. When people living with HIV/AIDS especially those who are taking ART medication are incarcerated. The health risk is due to treatment adherence of inmates and has proved to be challenging, particularly where food is scarce $[3,4]$.

There is convincing evidence on the relationship between the HIV epidemic and malnutrition, PLWHIV are more likely to become malnourished due to reduced food intake, side effects of medication, depression, poor absorption of nutrients and HIV-caused intestinal cell damage, increased energy needs as a result of virus replication and opportunistic infections, changes in the way the body uses the nutrients it receives or has stored. Malnutrition on the other hand, contributes to immune system impairment, making the body vulnerable to frequent illness, there by accelerating disease progression [5]. Additionally, appropriate nutrition can improve ART absorption and tolerance as well as improve quality of life of PLWHIV/AIDS [6-8].

${ }^{*}$ Corresponding author: Mehret Tesfu, College of Medicine and Health Sciences, Debre Markos University, Debre Markos, Ethiopia; Tel: 251913256221 ; E-mail: mercytes3@gmail.com

Received June 14, 2017; Accepted June 20, 2017; Published June 27, 2017

Citation: Kassa T, Alle A, Tesfu M (2017) Assessment of Nutritional Status and Associated Factors among Prisoners Living with HIVIAIDS in Kality Prison, Addis Ababa, Ethiopia. J AIDS Clin Res 8: 703. doi: 10.4172/2155-6113.1000703

Copyright: ( 2017 Kassa T, et al. This is an open-access article distributed under the terms of the Creative Commons Attribution License, which permits unrestricted use, distribution, and reproduction in any medium, provided the original author and source are credited. 


\section{Methods}

\section{Study design and period}

Institutional based cross-sectional quantitative study was conducted in Kality prison, Adis Abeba, Ethiopia, to assess the nutritional status and associated factors among prisoners living with HIV/AIDS, from February to March, 2016

\section{Study area}

Kality prison is a Federal state prison center which is located in Akaki/Kality subcity woreda 7 around $25 \mathrm{~km}$ from Addis Ababa, Ethiopia. It is located on the southern edge of the city and serves as the main prison of Ethiopia. The prison is divided into male and female zones, comprising around 4,000 sentenced prisoners currently, of which 3,400 were males and 600 were females. There were a total of approximately 550 prisoners living with HIV/AIDS currently, of which 300 were on pre ART and 250 were on ART. The institution has its own clinic with the composition of ART clinic, TB clinic, inpatient and outpatient departments, laboratory and pharmacy. The ART clinic is supervised by a trained BSC nurse and a data clerk.

\section{The source population}

All prisoners above 18 years and living with HIV/AIDS in Kality prison during the study period.

\section{The study population}

Prisoners who were above 18 years living with HIV/AIDS and randomly selected in Kality prison during the study period.

\section{Inclusion criteria}

Prisoners above 18 years old, living with HIV/AIDS, both pre ART and ART participants and who stayed in the prison for at least six months were included.

\section{Exclusion criteria}

Subjects who were severe0ly ill to participate as well as those who had incomplete information (CD4 cell count, WHO clinical stage, adherence status) in the registration book were excluded.

\section{Sample size determination and sampling procedure}

Sample size for the first objective: calculated using the formula for the estimation of single population proportion:

$$
\begin{aligned}
& n=z^{2} P Q / d^{2} \\
& n=\text { sample size required in the study } \\
& Z=95 \% \text { confidence level }(1.96)
\end{aligned}
$$

$\mathrm{P}=($ malnutrition among prisoners living with HIV/AIDS or the whole prisoners $50 \%)$

$\mathrm{Q}=1-\mathrm{p}(1-0.5)$

$\mathrm{d}^{2}=$ margin of error $(5 \%)$

$=384$

By considering a non response rate of $10 \%$, the sample size was 422

Sampling procedure: The HIV status was ascertained from the prisoner medical chart available at prisoners' card room. The total numbers of prisoners living with HIV/AIDS in Kality prison were around 550, From these 300 were on ART and 250 were on Pre- ART, and in order to select 422 participants from on ART and Pre-ART proportionately, mathematical equation was applied;

$\mathrm{n} 1=\left(\mathrm{N} 1{ }^{*} \mathrm{nf}\right) / \mathrm{Nf}$,

Where $\mathrm{n} 1$ : is the required sample size from ART clients,

N1: is total number of clients on ART,

$\mathrm{nf}$ is the sample size of this study,

$\mathrm{Nf}$ is total number of prisoners living with HIV/AIDS in Kality prison,

Where as

$\mathrm{n}_{2}=\left(\mathrm{N}_{2}^{*} \mathrm{n}_{\mathrm{f}}\right) / \mathrm{N}_{\mathrm{f}}$

Where $\mathrm{n}_{2}$ is the required sample size from Pre- ART clients and

N2 is total number of Pre-ART clients,

$\mathrm{n} 1=300 * 422 / 550=230, \mathrm{n} 2=250 * 422 / 550=192$,

Then by using systematic random sampling technique the first subject was selected after having a complete serial number list from using ART registration book $(\mathrm{k}=\mathrm{N} / \mathrm{n}=550 / 422=1.3)$. The first subject was selected by lottery and then every other subject was selected going on serially until the total number was achieved. Repeated visits were excluded by using codes, recording and checking their registration number of each client at the time of data collection.

\section{Variables of the study}

Dependent variable: The dependent variable was nutritional status of prisoners living with HIV/AIDS measured by BMI.

\section{Independent variables:}

Socio-demographic characteristics: Sex, age, educational status, marital status, source of support.

Medical and other related factors: Presence of eating difficulty, type of eating difficulty, presence of current/past OI, adherence status to ART, CD4 cell count status, Clinical stage.

HIV treatment related factors: Pre ART or on ART, duration of ART, type of ART currently in use, change of regimen of ART, reasons for changing regimen of ART, Side effects.

Prison related factors: Duration of stay in prison, Source of water.

Meal frequency: Frequency of source of energy, proteins, vitamins and minerals consumption.

\section{Operational definition}

Nutritional status: Nutritional status is the nutritional condition of an individual measured by Body Mass Index (BMI).

BMI: BMI is the ratio of weight for height squared $\left(\mathrm{wt} / \mathrm{ht}^{2}\right)$ measured by kilogram per meter squared $\left(\mathrm{kg} / \mathrm{m}^{2}\right)$.

Based on WHO BMI classification:

$<16 \mathrm{~kg} / \mathrm{m}^{2}=$ severe under nutrition

$16-16.99 \mathrm{~kg} / \mathrm{m}^{2}=$ moderate under nutrition

$17-18.49 \mathrm{~kg} / \mathrm{m}^{2}=$ mild under nutrition 
$18.5-24.99 \mathrm{~kg} / \mathrm{m}^{2}=$ normal nutrition status

$25-29.9 \mathrm{~kg} / \mathrm{m}^{2}=$ over weight

$\geq 30 \mathrm{~kg} / \mathrm{m}^{2}=$ obese

\section{WHO criteria for CD4 cell count classification}

$<200$ cells $/ \mathrm{mm}^{3}=$ severe immune deficiency

200-499 cells $/ \mathrm{mm}^{3}=$ moderate immune deficiency

$>500$ cells $/ \mathrm{mm}^{3}=$ mild immune deficiency

\section{Criteria for adherence classification:}

Good adherence: If average adherence is $>95 \%$ (he/she missed $\leq 2$ doses of 30 doses or $\leq 3$ doses of 60 doses).

Fair adherence: If average adherence is $85 \%-94 \%$ (he/she missed 3-5 doses of 30 doses or 4-8 doses of 60 doses).

Poor adherence: If average adherence is $<85 \%$ (he/she missed $\geq 6$ doses of 30 doses or $\geq 9$ doses of 60 doses).

WHO Clinical stage of established HIV infection: Stage I-Asymptomatic

Stage II-Mild symptoms

Stage III-Advanced symptoms

Stage IV-Severe symptoms

Eating difficulty: If a subject having any of the following symptoms at the time of data collection:

-Loss of appetite

-Nausea/vomiting

-Swallowing difficulty

-Others like heartburn, abdominal cramp, bloating

\section{Data collection procedure and quality control}

Data were collected using a structured interviewer's administered questionnaire which was developed in English and translated to Amharic language and back to English by language expert to keep the consistency of the questions. The questionnaire was pretested on five percent of study population in another prison center that was not included in the main study for consistency of understanding and completeness of data. The Amharic version was used for collecting information.

The height and weight of the patients was measured in light clothing and bare feet. The values were recorded to the nearest $0.1 \mathrm{~cm}$ and $0.1 \mathrm{~kg}$, respectively. Height was measured while the patients were standing erect in a Frankfurt position and the weight was measured on a standing scale. When it was not possible to measure height as in the case of people unable to assume erect positions, height could be estimated from arm span or demi span or knee height position.

Participants medical chart were reviewed for CD4 cell count status which was done every six months as routine follow up purpose. Their last visit CD4 cell count and clinical status were taken based on WHO clinical staging-Stage I, Stage II, Stage III, Stage IV to review clients clinical condition of their last month visit and their last month drug adherence status were obtained from clients medical chart.

Training was given for two data collectors and one supervisor who were diploma nurses on how to fill questionnaires and taking anthropometric measurements properly for one day duration. The principal investigator was supervised data collection process and reviewed every questionnaire for completeness.

\section{Data processing and analysis}

The collected data were cleared for completeness and consistencies and the responses in each question were coded for simplicity of data entry. The data were entered to Epi-info version 7.0 and exported to SPSS version 20.0 for analysis.

A binary logistic regression analysis was employed to examine the relationship between the outcome variable and independent variables. Those variables found to be significant at $\mathrm{P}<0.2$ in the binary logistic regression analysis were entered into multivariable logistic regression model and statistical significance was considered at $\mathrm{P}<0.05$. Results were presented with tables and graph as appropriate.

\section{Results}

\section{Socio demographic characteristics}

A total of 412 prisoners living with HIV/AIDS enrolled in this study with a response rate of $97.6 \%$. The majority of respondents were male $362(87.9 \%)$. The mean age of the respondents was 35.9 years with a standard deviation of \pm 9.6 years. The largest numbers of clients were in the age range of 30-39 years (36.7\%). From participants, $83(20.1 \%)$ had source of support and from these $62(74.7 \%)$ were from visitors (Table 1).

\section{Medical and other related problem of respondents}

The presence of eating difficulty were observed in 256 (62.1\%) of respondents and loss of appetite was the commonest $134(52.3 \%)$ followed by nausea/vomiting 81 (31.6\%). From respondents, HIV related symptoms were observed in $170(41.3 \%)$ and from these, chronic diarrhea $57(33.5 \%)$ was the leading cause. Majority of respondents were in WHO clinical stage I 181 (43.9\%), with CD4 cell count 200-499 (36.4\%) (Table 2).

\begin{tabular}{|c|c|c|c|}
\hline Variables & Category & Number & Percent \\
\hline \multirow[t]{2}{*}{ Sex } & Male & 362 & 87.9 \\
\hline & Female & 50 & 12.1 \\
\hline \multirow{4}{*}{ Age } & $18-29$ & 115 & 27.9 \\
\hline & 30-39 & 151 & 36.7 \\
\hline & $40-49$ & 106 & 25.7 \\
\hline & $\geq 50$ & 40 & 9.7 \\
\hline \multirow{4}{*}{ Marital status } & Single & 193 & 46.8 \\
\hline & Married & 87 & 21.1 \\
\hline & Divorced & 104 & 25.2 \\
\hline & Widowed & 28 & 6.8 \\
\hline \multirow[t]{2}{*}{ Educational status } & Formal education & 270 & 65.5 \\
\hline & Have no formal education & 142 & 34.5 \\
\hline \multirow{2}{*}{$\begin{array}{l}\text { Presence of source of } \\
\text { support }\end{array}$} & Yes & 83 & 20.1 \\
\hline & No & 329 & 79.9 \\
\hline \multirow[b]{3}{*}{ Source of support } & Visitors & 62 & 74.7 \\
\hline & Prisoners general committee & 19 & 22.9 \\
\hline & $\begin{array}{l}\text { Currently working in Prison } \\
\text { Technical and vocational } \\
\text { institute }\end{array}$ & 2 & 2.4 \\
\hline
\end{tabular}

Table 1: Socio-demographic characteristics of prisoners living with HIVIAIDS at Kality prison center, Addis Ababa, Ethiopia February 24-March 30, 2016, $(n=412)$. 
Citation: Kassa T, Alle A, Tesfu M (2017) Assessment of Nutritional Status and Associated Factors among Prisoners Living with HIVIAIDS in Kality Prison, Addis Ababa, Ethiopia. J AIDS Clin Res 8: 703. doi: 10.4172/2155-6113.1000703

Page 4 of 6

\section{Anti HIV treatment related status}

Majority of participants were on ART 230 (55.8\%), and the commonest ART regimen was 1e 137 (59.6\%). From participants, 20 (4.9\%) changed ART regimen with a major reason of side effects of ART medication 16 (80.0\%), from these the commonest observed side effect was vomiting 6 (37.5\%), followed by rush $4(25.0 \%)$. From respondents, 38 (9.2\%) interrupted ART medication, the commonest reason were side effects of medication 13 (34.2\%) followed by lack of adequacy of food $12(31.6 \%)$ (Table 3$)$.

\section{Prison related conditions}

The majority of prisoners living with HIV/AIDS stayed in the prison for more than 5years duration (53.6\%), followed by 1-5 years $(25.5 \%)$ and less than one year 86 (20.9\%). All respondents have got drinking water from public tap water.

\section{Meal frequency of respondents}

Consumption of source of energy: Results showed that, 396 (96.1\%) of prisoners living with HIV/AIDS did not consume maize meal for the whole week. Only 12 (2.9\%) of respondents consumed maize meal once per week. Large number of respondents did not consume rice 354 (85.9\%) and sweet potato 378 (91.7\%) for the whole week. Majority of participants received their source of energy from wheat 379 (92.0\%) every day of the week (Table 4).

Consumption of source of protein: Results showed that, majority of respondents got their source of protein from bean 357 (86.7\%), followed by milk $3(0.7 \%)$ every day of the week (Table 5 ).

Consumption of source of vitamins and minerals: Results showed that, majority of participants did not consume mango 402 (97.6\%) orange 396 (96.1\%), salad 379 (92.0\%) and cabbage $370(89.8 \%)$ for the whole week. Only 4 (1.0\%) of respondents consumed banana, followed by papaya, salad and cabbage in equal proportion $2(0.5 \%)$ every day for a week (Table 6).

Nutritional status of respondents: Majority of respondents had normal nutritional status $57.0 \%$. The prevalence of the overall malnutrition among respondents was $43 \%$. From this $0.5 \%, 8.0 \%$ and $26.7 \%$ were under weight; moderately underweight and mildly underweight respectively.

\begin{tabular}{|l|l|c|c|}
\hline Problem & Category & Number & Percent \\
\hline Presence of eating difficulty & Yes & 256 & 62.1 \\
& No & 156 & 37.9 \\
Type of eating difficulty & Loss of appetite & 134 & 52.3 \\
& Nausea/vomiting & 81 & 31.6 \\
Presence of HIV related symptom & Swallowing difficulty & 41 & 16.0 \\
& Yes & 170 & 41.3 \\
Type of symptom & No & 242 & 58.7 \\
& Chronic diarrhea & 57 & 33.5 \\
& Chronic cough & 52 & 30.6 \\
& Nervous system infection & 12 & 7.1 \\
CD4 cell count (WHO criteria) & Oral thrush & 42 & 24.7 \\
& *other & 7 & 4.1 \\
& $<200$ & 142 & 34.5 \\
Clinical stage (WHO criteria) & $\mathbf{2 0 0 - 4 9 9}$ & 150 & 36.4 \\
& $\mathbf{> 5 0 0}$ & 120 & 29.1 \\
& Stage I & 181 & 43.9 \\
& Stage II & 69 & 16.7 \\
& Stage III & 143 & 34.7 \\
& Stage IV & 19 & 4.6 \\
\hline
\end{tabular}

*other - Extra pulmonary Tuberculosis, Anemia, Weight loss

Table 2: Medical and other related problem of prisoners living with HIVIAIDS at Kality prison center, Addis Ababa, Ethiopia February 24-March 30, 2016, $(n=412)$.

\begin{tabular}{|c|c|c|c|}
\hline Treatment condition & Category & Number & Percent \\
\hline \multirow{3}{*}{ ART status } & Pre ART & 182 & 44.2 \\
\hline & ART & 230 & 55.8 \\
\hline & $1 c$ & 46 & 20.0 \\
\hline \multirow{5}{*}{$\begin{array}{l}\text { Type of ART regimen } \\
\text { currently in use }\end{array}$} & $1 d$ & 30 & 13.0 \\
\hline & $1 e$ & 137 & 59.6 \\
\hline & $1 f$ & 13 & 5.7 \\
\hline & Second line & 4 & 1.7 \\
\hline & $\leq 3$ months & 90 & 39.1 \\
\hline \multirow[t]{4}{*}{ Length of treatment } & 3-6 months & 25 & 10.9 \\
\hline & $\geq 6$ months & 115 & 50.0 \\
\hline & Yes & 20 & 4.9 \\
\hline & No & 210 & 51.0 \\
\hline \multirow[t]{2}{*}{ Change of ART regimen } & Side effect & 16 & 80.0 \\
\hline & Resistance & 3 & 15.0 \\
\hline \multirow{3}{*}{$\begin{array}{l}\text { Reason for change of } \\
\text { regimen }\end{array}$} & TB treatment & 1 & 5.0 \\
\hline & Neuropathy & 3 & 18.8 \\
\hline & Anemia & 3 & 18.8 \\
\hline \multirow{4}{*}{ Type of side effect } & Vomiting & 6 & 37.5 \\
\hline & Rash & 4 & 25.0 \\
\hline & Yes & 38 & 9.2 \\
\hline & No & 192 & 46.6 \\
\hline \multirow[t]{2}{*}{ Interruption of treatment } & Lack of food adequacy & 12 & 31.6 \\
\hline & Lack of ART medication & 4 & 10.5 \\
\hline \multirow{4}{*}{$\begin{array}{l}\text { Reason for interruption of } \\
\text { treatment }\end{array}$} & Side effects of medication & 13 & 34.2 \\
\hline & $\begin{array}{l}\text { Due to transfer to zonal } \\
\text { prison center }\end{array}$ & 6 & 15.8 \\
\hline & ${ }^{* *}$ Other & 3 & 7.9 \\
\hline & Good & 190 & 82.6 \\
\hline \multirow[t]{2}{*}{ Adherence status } & Fair & 10 & 4.3 \\
\hline & Poor & 30 & 13.0 \\
\hline
\end{tabular}

${ }^{* *}$ Other - Lack of transfer in paper, Loss of ART identification card, Lack of availability of guard to bring the client to the clinic at the time of appointment, Feeling of hopelessness

Table 3: Anti HIV treatment related status of prisoners living with HIVIAIDS at Kality prison center, Addis Ababa, Ethiopia February 24-March 30, 2016, $(n=412)$.

\section{Factors associated with nutritional status}

Association between dependent variable and every independent variable were tested with binary logistic regressions. The result showed that sex, age, educational status, presence of source of support, presence of eating difficulty, presence of HIV related symptom and CD4 cell count status had association with nutritional status of prisoners living with HIV/AIDS in Kality prison center.

Thereafter, multivariable logistic regression analysis was applied to control confounders and identify the actual factors that are significantly associated with nutritional status of prisoners living with HIV/AIDS. Those variables found to be significant from binary logistic analysis at $\mathrm{p}$-value $<0.2$ were entered into the multivariable logistic regression model. After analysis, sex, age, presence of source of support, presence of eating difficulty and presence of HIV related symptom, were found to be significantly associated with nutritional status.

Female respondents were $92 \%$ times less likely to develop malnutrition than male respondents (AOR 0.08 [95\% CI 0.02, 0.42]), and those who were in the age range of $\geq 50$ were eight times more likely to be malnourished with (AOR 8.68 [95\% CI 1.59, 47.28]). Participants who had source of support were $97 \%$ times less likely to be malnourished (AOR 0.03 [95\% CI 0.01, 0.13]). Persons with no eating difficulty were $95 \%$ times less likely to develop malnutrition with (AOR 0.05 [95\% CI 0.01, 0.19]). Respondents with presence of HIV related symptoms were two times more likely at risk to develop malnutrition (AOR 2.73 [95\% CI 1.09, 5.03]). 


\begin{tabular}{|c|c|c|c|c|c|c|c|c|}
\hline \multicolumn{9}{|c|}{ Source of energy(Cereals, roots and tubers consumption) } \\
\hline \multirow{2}{*}{ Intake per week(times) } & \multicolumn{2}{|c|}{ Maize } & \multicolumn{2}{|c|}{ Wheat } & \multicolumn{3}{|c|}{ Rice } & Sweet potato \\
\hline & Number & Percent & Number & Percent & Number & Percent & Number & Percent \\
\hline Zero & 396 & 96.1 & 1 & 0.2 & 354 & 85.9 & 378 & 91.7 \\
\hline One & 12 & 2.9 & 2 & 0.5 & 24 & 5.8 & 25 & 6.1 \\
\hline Two & 1 & 0.2 & 8 & 1.9 & 13 & 3.2 & 3 & 0.7 \\
\hline Three & 2 & 0.5 & 4 & 1.0 & 3 & 0.7 & 2 & 0.5 \\
\hline Four & 1 & 0.2 & 17 & 4.1 & 4 & 1.0 & 1 & 0.2 \\
\hline Five & 0 & 0.0 & 1 & 0.2 & 0 & 0.0 & 0 & 0.0 \\
\hline Six & 0 & 0.0 & 0 & 0.0 & 0 & 0.0 & 0 & 0.0 \\
\hline Seven & 0 & 0.0 & 379 & 92.0 & 14 & 3.4 & 3 & 0.7 \\
\hline
\end{tabular}

Table 4: Frequency(times per week) consumption of sources of energy of prisoners living with HIVIAIDS at Kality prison center, Addis Ababa, Ethiopia February 24-March $30,2016,(n=412)$

\begin{tabular}{|c|c|c|c|c|c|c|c|c|c|c|}
\hline \multirow{2}{*}{$\begin{array}{c}\text { Intake per } \\
\text { week(times) }\end{array}$} & \multicolumn{2}{|c|}{ Bean } & \multicolumn{2}{|c|}{ Meat } & \multicolumn{2}{|c|}{ Milk } & \multicolumn{2}{|c|}{ Fish } & \multicolumn{2}{|c|}{ Egg } \\
\hline & Number & Percent & Number & Percent & Number & Percent & Number & Percent & Number & Percent \\
\hline Zero & 7 & 1.7 & 343 & 83.3 & 282 & 68.4 & 394 & 95.6 & 368 & 89.3 \\
\hline One & 2 & 0.5 & 50 & 12.1 & 106 & 25.7 & 14 & 3.4 & 28 & 6.8 \\
\hline Two & 4 & 1.0 & 10 & 2.4 & 11 & 2.7 & 3 & 0.7 & 11 & 2.7 \\
\hline Three & 9 & 2.2 & 2 & 0.5 & 8 & 1.9 & 0 & 0.0 & 1 & 0.2 \\
\hline Four & 13 & 3.2 & 3 & 0.7 & 2 & 0.5 & 1 & 0.2 & 1 & 0.2 \\
\hline Five & 13 & 3.2 & 1 & 0.2 & 0 & 0.0 & 0 & 0.0 & 1 & 0.2 \\
\hline Six & 7 & 1.7 & 1 & 0.2 & 0 & 0.0 & 0 & 0.0 & 0 & 0.0 \\
\hline Seven & 357 & 86.7 & 2 & 0.5 & 3 & 0.7 & 0 & 0.0 & 2 & 0.5 \\
\hline
\end{tabular}

Table 5: Frequency(times per week) consumption of sources of proteins of prisoners living with HIV/AIDS at Kality prison center, Addis Ababa, Ethiopia February 24-March $30,2016,(n=412)$

\begin{tabular}{|c|c|c|c|c|c|c|c|c|c|c|c|c|}
\hline \multicolumn{13}{|c|}{ Source of vitamins and minerals(fruits and vegetables consumption) } \\
\hline \multirow{2}{*}{$\begin{array}{c}\text { Intake per } \\
\text { week(times) }\end{array}$} & \multicolumn{2}{|c|}{ Banana } & \multicolumn{2}{|c|}{ Mango } & \multicolumn{2}{|c|}{ Orange } & \multicolumn{2}{|c|}{ Papaya } & \multicolumn{2}{|c|}{ Salad } & \multicolumn{2}{|c|}{ Cabbage } \\
\hline & No. & Percent & No. & Percent & No. & Percent & No. & Percent & No. & Percent & No. & Percent \\
\hline Zero & 349 & 84.7 & 402 & 97.6 & 396 & 96.1 & 397 & 96.4 & 379 & 92.0 & 370 & 89.8 \\
\hline One & 32 & 7.8 & 5 & 1.2 & 11 & 2.7 & 7 & 1.7 & 22 & 5.3 & 19 & 4.6 \\
\hline Two & 16 & 3.9 & 0 & 0.0 & 1 & 0.2 & 1 & 0.2 & 5 & 1.2 & 13 & 3.2 \\
\hline Three & 9 & 2.2 & 4 & 1.0 & 3 & 0.7 & 3 & 0.7 & 2 & 0.5 & 6 & 1.5 \\
\hline Four & 2 & 0.5 & 1 & 0.2 & 1 & 0.2 & 2 & 0.5 & 1 & 0.2 & 1 & 0.2 \\
\hline Five & 0 & 0.0 & 0 & 0.0 & 0 & 0.0 & 0 & 0.0 & 0 & 0.0 & 0 & 0.0 \\
\hline Six & 0 & 0.0 & 0 & 0.0 & 0 & 0.0 & 0 & 0.0 & 1 & 0.2 & 1 & 0.2 \\
\hline Seven & 4 & 1.0 & 0 & 0.0 & 0 & 0.0 & 2 & 0.5 & 2 & 0.5 & 2 & 0.5 \\
\hline
\end{tabular}

Table 6: Frequency(times per week) consumption of sources of vitamins and minerals of prisoners living with HIV/AIDS at Kality prison center, Addis Ababa, Ethiopia February 24-March 30, 2016, $(n=412)$

\section{Discussion}

In this study, the prevalence of malnutrition in prisoners living with HIV/AIDS was $43 \%$. The prevalence was higher than studies done in Gueckedou, Guinea (38\%) [9], Oyo, Nigeria (39\%) [10], prisons among the general prisoners and a study done in selected prisoners of Tanzania among prisoners living with HIV/AIDS 23\% [2]. The discrepancy of malnutrition status might be due to the existence of different socioeconomic factors of the study areas, partly due to the country's limited resources and inadequate physical activity and feeding habits of the prisoners.

Females were $92 \%$ times less likely to develop malnutrition (AOR 0.08 [ $95 \%$ CI $0.02,0.42]$ ) than males, this might be due to the coordinated effort to improve the situation by female prisoners administrative office that put female prisoners often in a relatively better state of health and nutrition than male prisoners and generally benefit from better living conditions, access to water and food in the study area.

Subjects in the age group $\geq 50$ were eight times more likely to develop malnutrition (AOR 8.68 [95\% CI 1.59, 47.28]) than other age groups. This might be due to older adults were prone to age-related diseases, functional impairment and physical inability that may interfere with the maintenance of a good nutritional status [11].

In this study, respondents who had source of support were $97 \%$ times less likely to develop malnutrition (AOR 0.03 [95 \% CI 0.01 , $0.13]$ ) than who had no source of support. This could be due to people who are socially isolated and that cannot attain nutritious foods due to low income and no nutritional support are most associated with inadequate diet and disease that leads to malnutrition [12-14].

Participants who had not suffered from eating difficulties were 95\% times less likely to develop malnutrition (AOR 0.05 [95\% CI 0.01, 0.19]). This finding is in accordance with the results of former studies conducted in Butajira [5] and Bahir dar [15] among PLWHIV/AIDS. This might be due to reduction of food consumption due to eating difficulties like loss of appetite, vomiting, nausea and oral thrush as well as with the food eaten is poorly absorbed, the body draws on its reserve stores of energy from body fat and protein from muscle. As a result, the person loses weight because body weight and muscles are lost [16].

With regard to HIV/AIDS related symptoms, those who developed symptoms in the past six months were two times more malnourished (AOR 2.73 [95\% CI 1.09, 5.03]) than those who were free of symptoms. In places where there are inadequate food supplies, many PLWHIV may already be malnourished. Their weakened immune systems further increase their vulnerability to opportunistic infections. Symptoms that accompany infections such as loss of appetite, diarrhea and fever lead to further reduced food intake, poor nutrition absorption, nutrient loss 
Citation: Kassa T, Alle A, Tesfu M (2017) Assessment of Nutritional Status and Associated Factors among Prisoners Living with HIV/AIDS in Kality Prison, Addis Ababa, Ethiopia. J AIDS Clin Res 8: 703. doi: 10.4172/2155-6113.1000703

Page 6 of 6

\begin{tabular}{|c|c|c|c|c|c|c|}
\hline \multirow[b]{2}{*}{ Variables } & \multirow[b]{2}{*}{ Categories } & \multicolumn{2}{|c|}{ Nutritional status } & \multirow[b]{2}{*}{ COR $(95 \% \mathrm{Cl})$} & \multirow[b]{2}{*}{ AOR (95\%Cl) } & \multirow[b]{2}{*}{ P-values } \\
\hline & & Normal & Malnourished & & & \\
\hline $\begin{array}{l}\text { Educational status } \\
\text { Presence of source } \\
\text { of support } \\
\text { Presence of eating } \\
\text { difficulty } \\
\text { Presence of HIV } \\
\text { related symptom } \\
\text { CD4 cell count } \\
\text { ART status }\end{array}$ & $\begin{array}{c}\text { Male } \\
\text { Female } \\
18-29 \\
30-39 \\
40-49 \\
\geq 50 \\
\text { Formal education } \\
\text { No formal education } \\
\text { Yes } \\
\text { No } \\
\text { Yes } \\
\text { No } \\
\text { Yes } \\
\text { No } \\
<200 \\
200-499 \\
>500 \\
\text { Pre ART } \\
\text { ART }\end{array}$ & $\begin{array}{c}212 \\
23 \\
78 \\
62 \\
76 \\
19 \\
177 \\
\\
58 \\
73 \\
162 \\
88 \\
147 \\
15 \\
220 \\
37 \\
83 \\
115 \\
99 \\
136\end{array}$ & $\begin{array}{c}150 \\
27 \\
37 \\
89 \\
30 \\
21 \\
93 \\
\\
84 \\
10 \\
167 \\
168 \\
9 \\
155 \\
22 \\
105 \\
67 \\
5 \\
83 \\
94\end{array}$ & $\begin{array}{c}1 \\
1.66(0.92,3.01) \\
1.20(0.67,2.13) \\
3.64(2.14,6.20) \\
1 \\
2.80(1.32,5.93) \\
1 \\
\\
2.76(1.81,4.19) \\
7.53(3.75,15.08) \\
1 \\
1 \\
0.03(0.02,0.07) \\
0.01(0.00,0.02) \\
1 \\
3.52(2.15,5.76) \\
1 \\
0.05(0.02,0.14) \\
0.82(0.56,1.22) \\
1\end{array}$ & $\begin{array}{c}1 \\
0.08(0.02,0.42) \\
0.36(0.10,1.28) \\
2.16(0.76,6.12) \\
1 \\
8.68(1.59,47.28) \\
1 \\
0.61(0.23,1.63) \\
0.03(0.01,0.13) \\
1 \\
1 \\
0.05(0.01,0.19) \\
2.73(1.09,5.03) \\
1 \\
1.48(0.58,3.80) \\
1 \\
0.26(0.05,1.49) \\
- \\
1\end{array}$ & $\begin{array}{l}0.00 \\
0.00\end{array}$ \\
\hline
\end{tabular}

Table 7: Logistic regression of BMI with independent variables among prisoners living with HIVIAIDS at Kality prison center, Addis Ababa, Ethiopia February24-March 30, 2016, $(n=412)$

and altered metabolism; all of these contribute to malnutrition which in turn further weaken the immune system [17].

\section{Conclusion}

The prevalence of underweight was very high among prisoners living with HIV/AIDS in this area. Sex, age, presence of source of support, presence of eating difficulty and presence of HIV related symptoms were predictors of malnutrition among prisoners living with HIV/AIDS in Kality prison. From participants' male prisoners and old age respondents were more likely to become malnourished.

\section{Recommendation}

Improving living conditions of male prisoners like female prisoners by prison administrative bodies. Improving financial capacity of the prisoners by providing vocational training and able to work in the compound. The prison administrative body should give emphasis on increasing diversified food. Further studies on the effect of nutritional support on malnourished respondents which was not included on this study are worth to be investigated by other researchers.

\section{Ethical Approval}

Ethical clearance and formal letter was obtained from health research and post graduating institutional research ethical review committee of public health and medical science of Debre Markos University.

\section{Competing Interests}

There is no competing interest with the presented data as external data collectors collected it. There was not financial interest between the funder and the research area community and us. We, the researchers, have no any form of competing financial and non-financial interest between ourselves

\section{Authors' Contributions}

We, the three, have significant contribution in the proposal development, defending for fund obtaining, data collection and data analysis and manuscript preparation process of this work.

\section{Acknowledgement}

We are grateful to Debre Markos University and GAMBY College of Medical
Science. We also acknowledge Kality Prison administrative bodies for their cooperation and granting us permission to conduct this study, our study participants for providing the necessary information and the data collectors for collecting the data carefully.

\section{References}

1. The free encyclopedia (2015) Definition of prison.

2. Mwakyoso ML (2013) Nutritional assessment of prisoners living with HIVIAIDS in selected prisons in Tanzania. Sokoine University of Agriculture. Morogoro, Tanzania, p: 134

3. UNAIDS (2014) The gap report. UNAIDS, p: 422.

4. Federal Bureau of Prisoners Clinical Practice Guidelines (2014) Koess, p: 16.

5. Dereje J, Baye G, Dagnachew M, Mola M (2015) Prevalence of malnutrition and its associated factors among adult People living with HIVIAIDS receiving antiretroviral therapy at Butajira Hospital, Southern Ethiopia. BMC Nutr 1: 5.

6. Thape R, Amatya A, Pahari D, Bam K, Newman M (2015) Nutritional status and its association with quality of life among PLWHIV attending public ART sites of Kathmandu vally, Nepal. AIDS Res Ther 12: 14.

7. FANTA (2001) HIVIAIDS: A guide for nutrition, care and support. 7: 56.

8. UNAIDS (2014) Food and nutrition. UNAIDS, p: 24.

9. MSF (2009) Guinea: MSF exposes emergency nutritional and medical needs in Guinean prisons.

10. Akinlotan J, Nupo S, Olorode O (2010) Assessment of nutritional status of inmates in Oyo state, Nigeria 2: 8.

11. The Dairy Council (2016) Under nutrition in older people.

12. National Institute for Health and Care Excellence: Malnutrition (2009) NIH.

13. FAO (2001) The impact of HIVIAIDS on Food security. Committee on world food security.

14. Unite for sight (2015) Social determinants of malnutrition.

15. Wasie B, KebedeY, Yibrie A (2010) Nutritional status of adults living with HIVI AIDS at the university of Gondar Referal hospital, North West Ethiopia. Health Biomed Science 3: 12.

16. FAO (2015) Living well with HIVIAIDS. A manual on nutritional care and support for people living with HIVIAIDS.

17. UNICEF (2015) Nutrition and HIV: Nutrition module12. 